\title{
Wither Elites? The Role of Elite Credibility and Knowledge in Public Perceptions of Foreign Policy
}

\author{
Danielle Lupton* \\ Department of Political Science \\ Colgate University \\ Hamilton, NY13346 \\ Email: dlupton@colgate.edu
}

\author{
Clayton Webb \\ Department of Political Science \\ University of Kansas \\ Lawrence, KS 66045 \\ Email: webb767@ku.edu
}

February 5, 2021

\begin{abstract}
Existing theories of foreign policy opinion formation tend to treat elites as a black-box category for members of the non-public. This misses important nuances in public perceptions of elites. We argue that elite vocation serves as an important source cue, signaling elite access to information and elite knowledge that can be brought to bear on that information. We use a survey experiment to evaluate our hypotheses comparing four types of elites: elected officials, academics, career-professionals, and members of the media. We find that, even accounting for partisanship, people still evaluate elites as knowledgeable and credible. There are also important differences in public perceptions of elites that should be accounted for in our theories of opinion formation. These findings have important implications for the en-vogue death of expertise argument as well as research on public perceptions of foreign policy and public opinion formation.
\end{abstract}

${ }^{*}$ Corresponding Author 


\section{Introduction}

As an expert on foreign policy, I can tell you that my expertise no longer matters. This is Tom Nichols's message in his popular 2017 Oxford University Press book, The Death of Expertise: The Campaign Against Established Knowledge and Why it Matters. Nichols argues the diffusion of information through new and varied channels, the rise of populism, and increased partisan polarization in the United States have led the public to discount the expertise of academics, career bureaucrats, members of the media, and elected officials. The book has enjoyed a considerable amount of success, commercially and across the academy $!^{1}$ More importantly, Nichols's lament is shared by a growing group of academics and public intellectuals interested in the implications of this turn from knowledge for the future of American politics and democracy (e.g., Brennan 2016; Kakutani 2019). This perspective raises a related, albeit less pressing, problem for scholars interested in public opinion: it is fundamentally at odds with many of the principal theories we use to understand how the public formulates opinions about foreign policy.

According to a large and longstanding literature, the public takes cues from more knowledgable segments of the population to develop attitudes and beliefs about complex foreign policy issues on which the public is generally uninterested and not well informed (Baum and Groeling 2010). Foreign policy scholars provide a plethora of evidence that the public trusts foreign policy elites and relies on their expert credibility and cognizance when forming opinions on international affairs (e.g., Berinsky 2007: Baum and Groeling 2009: Saunders 2015). But if expertise is dead, this public trust must have been broken. Accordingly, these two lines of logic are fundamentally incompatible. Does the public still trust the expertise of elites or have trends in contemporary politics so reshaped information dynamics that our theories of opinion formation must be revised?

\footnotetext{
${ }^{1}$ As of January 7, 2021, the number of Google Scholar citations for The Death of Expertise stands at an impressive 663 since its publication in February 2017.
} 
We argue for equanimity. Expertise is not dead but we need to reconsider the way we think about foreign policy elites. Since Zaller (1992), the terms "political elites" and "partisan elites" have often been deployed as black-boxes, lumping together members of the non-public in theories of public opinion formation. Elected officials, policy experts, and members of the media are often treated as a single group that are elite vis-a-vis the public because they have access to more information. We argue that not all these "elites" enjoy the same deference in American politics because these groups derive credibility from different sources, and the public can perceive these differences. Elected officials have access to specialized information and derive credibility from their offices. Academics and career professionals derive credibility from their education and experience. Media members are more informed than most members of the public but lack the specialized credentials of the other groups. These differences suggest a well-defined hypothesis about the relative credibility of these distinct classes of elites. We use a $4 \times 2$ between group factorial survey experiment to test this hypothesis along with a parallel hypothesis accounting for the role of partisanship in perceptions of elite credibility. We find support for both our hypotheses and present an auxiliary analyses highlighting the role of perceptions of elite knowledge as the critical causal mechanism.

Our study carries three critical implications for the literature on public opinion of foreign policy. First, our results are important for all work that examines the role of elites in public opinion formation. What does it mean that "elite cues matter" if we don't know who the elites are or why their opinions are important? Our work shows not all elites carry the same status in the eyes of the public, and we provide a clear causal mechanism explaining this variation. Second, our study carries implications for the recent trend in international relations survey and experimental research where investigators recruit "elites" as subject pools. We provide a framework investigators can use to select appropriate varieties of elites to test their theories. Third, our work directly challenges the en vogue argument that expertise is dead. While we find partisanship plays an important role in shaping public perceptions of elites, we also show that all the groups Zaller (1992) highlights - elected officials, academics, career officials, and members of the media - continue to be perceived as credible sources of information in the eyes of the public. Partisanship and the diffusion of information may 
have reshaped public perceptions of elites, but these trends have not killed expertise as a source of credibility. In fact, our results indicate the public is discerning about which "experts" are worthy of deference, not generally dismissive of expertise altogether.

\section{The Role of Elites in Foreign Policy Opinion Formation}

Views on the origins and relevance of public opinion towards foreign policy have evolved over time. The perspective on the public was decidedly pessimistic through the first half of the 20th century. The Almond-Lippmann consensus held that public opinion on most foreign policy issues had no depth or structure (Almond 1950) and that the views of the public could be easily manipulated (Holsti 2004). Many accepted this perspective because it corresponded to several lines of argument within the dominant international relations paradigm of the time, Realism. This era of pessimism was followed by a period of relative optimism. New research suggested that, while most people did not maintain a sophisticated understanding of international affairs, public opinions about foreign policy issues did have predictable structures and the public reacted prudently to international events

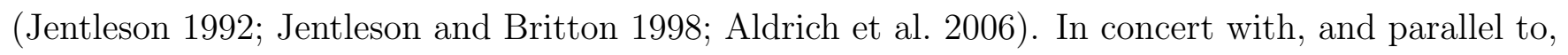
this optimistic turn came an increased interest in the sources of the public's prudent preferences.

Extant research indicates most people collect what meager information they consume about international affairs from two major sources. The most direct source of information is information from other members of the public. Kertzer and Zeitzoff (2017) show that many people develop opinions about foreign policy issues based on cues they receive from their peers. These cues form the "mesofoundations" of public opinion, the social context and networks in which citizens are embedded (Kertzer and Zeitzoff 2017, 546). While these cues have important consequences for public opinion, the relevance of mesofoundations is a relatively novel idea.

More attention has been paid to the role of elites in shaping foreign policy opinion. Scholars find the nature and structure of elite discourse can influence public opinion about conflict (Berinsky 
2007), international cooperation (Hooghe and Marks 2005), and foreign aid (Milner and Tingley 2013). While elite cues affect opinion about domestic politics and policy as well, the role of elites in opinion formation has been viewed as particularly important in the area of foreign policy because the public tends to be ill informed about international affairs (Baum and Groeling 2009: Saunders 2015).

Taking the preeminence of elite discourse in foreign policy opinion formation as given, contemporary work has tended to focus on the way elite discourse influences public opinion. Elite discourse does not simply trickle down to the masses. Rather, the nature and content of the discourse matters. Elite discourse provides a stronger signal to the public when there is consensus among elites (Kreps 2010; Saunders 2015), as division among elites causes people to default to their partisan predispositions (Berinsky 2009). In this vein, there is evidence that foreign policy issues which receive significant media coverage tend to be more polarized, while more obscure policy issues are more sensitive to elite discourse (Druckman and Leeper 2012). Guisinger and Saunders (2017) argue that variation across issue context is crucial to cue-givers' abilities to influence voters' attitudes about foreign policy issues. They find "systematic variation across issues in the extent to which public attitudes are movable, and when particular messengers are most effective at shifting opinions" Guisinger and Saunders 2017, 425). On some issues the public looks to partisan elites, but on other issues voters look for politically unaffiliated experts. This suggests the colloquial view of elites as primarily consisting of politicians is too narrow, an issue we address in more detail below.

So, who are these elites? This simple question does not produce a simple answer. The boundaries for who constitutes an elite or foreign policy elite are not well defined. According to Pareto (1935), elites are those who have attained special status in their chosen social hierarchies. This is not limited to politicians (Mosca 1939), although such "political" or "governing" elites hold special status given their power to effect change (Lasswell 1936; Nadel 1956). Indeed, elites can be considered those who are at the "top" of their respective "interest group" or "activity which affects politics" (Parry 1969, 68). Yet as Zuckerman (1977) notes, inclusive definitions create ambiguity 
over who constitutes an elite more broadly and confusion about which actors are considered political elites.

Enter John Zaller (1992), whose seminal work The Nature and Origins of Mass Opinion, defines political elites and explains the role of elites in public opinion formation:

Citizens in large societies are dependent on unseen and usually unknown others for most of their information about the larger world...The "others" on whom we depend, directly or indirectly, for information about the world are, for the most part, persons who devote themselves full time to some aspect of politics or public affairs - which is to say, political elites. These elites include politicians, higher-level government officials, journalists, some activists, and many kinds of experts and policy specialists. Even when we learn from friends or family members about some aspect of public affairs, often we may still be secondhand consumers of ideas that originated more distantly among some type of elite. (7)

Here, Zaller (1992) provides a list of potential elites who create the knowledge and information the general public consumes about policy and politics. The information these elites provide comes to the public through different channels: one is through media outlets (newspapers, television, podcasts, etc.) and another is from other members of the public through person-to-person interactions or social media. In either case, Zaller (1992) and his acolytes in the realm of foreign policy and international relations maintain that elites play an important role in public opinion formation because elites shape the information environment surrounding foreign policy issues. While Zaller's definition seems reasonable, important issues arise when one considers the content of this often-referenced definition and others like it.

First, the contents of the definition raise a number of basic questions which, to our knowledge, have never been subjected to empirical scrutiny. Namely, does the public perceive all of these types of people as elite and are all of these types of people perceived the same way? While the classes 
of individuals listed by Zaller (1992) certainly have access to knowledge and information that set them apart from members of the general public, these classes of people vary in important ways. Why would we think a Senator is viewed the same way as a cable news anchor? What evidence do we have that elected officials and media personalities are viewed the same way as academics? Research shows the willingness of people to believe politicians (Druckman, Peterson and Slothuus 2013), journalists (Gunther et al. 2001), or activists greatly depends on the partisanship of the individuals or the perceived partisanship of their causes. This militates against the notion that these classes of people are treated with uniform deference. This notion of uniform deference has never been considered and, even if one would be willing to acknowledge there are differences among the groups, we are not aware of any theory or empirical evidence speaking to these differences.

Second, even if the elite classes highlighted by Zaller (1992) once held a special place in American politics, recent trends in political science and popular culture suggest that public confidence in the elite political class has frayed since the end of the twentieth century. Research shows public trust in government has been declining steadily over the last 20 years (Chanley, Rudolph and Rahn 2000; Hetherington and Rudolph 2015), with strong evidence that people have little trust in government when their party does not hold the White House (Hetherington 2015). Partisan considerations influence whether an appointed official will-or-will not be believed by an individual Grynaviski 2010). Kertzer and Zeitzoff (2017) find evidence that the signals people receive from friends and family about foreign policy are more important than the signals they receive from elected officials $:^{2}$

The idea that members of the public defer to elites in the realm of foreign policy also contrasts with a view which is becoming increasingly popular with a number of public intellectuals, that expertise is dead. The death of expertise position posits the public no longer trusts "expert" opinion for a variety of reasons. First, some suggest the diffision of knowledge across new forms of media, especially the internet, has reduced the information asymmetry between the public and

\footnotetext{
${ }^{2}$ Importantly, for our study, Kertzer and Zeitzoff (2017) test the difference between signals from one's social network against signals sent by members of the U.S. Senate.
} 
elites (Nichols 2017; Hayes 2012). This, in turn, reduces the need for the public to rely on these experts as one can simply become - or buy into the illusion that one is - an expert in one's own right. Second, proponents of this perspective suggest the rise of populism directly undercuts the value the public places on elites and their institutions (Brennan 2016; Kakutani 2019). As a result, the public discounts the arguments and expertise provided by traditional elites.

Finally, adherents to the death of expertise argument point to increased partisan polarization in the United States as another force that has undermined the credibility of elites (Drezner 2017; Kavanaugh and Rich 2018; Kakutani 2019). Republicans and conservatives, in particular, are becoming increasingly distrustful of elite institutions, particularly the academy. As academics, we would like to believe the credentials we have suffered to acquire and maintain lend us credibility with the masses but there are many who believe this is a naïve pretension. For example, Nisbet, Cooper and Garrett (2015) argue public trust in scientific messaging is influenced by the partisanship of the scientists and the perceived partisanship of their messages. People tend to reject ideas, regardless of the source or basis of scientific evidence, that are inconsistent with their world views (Lewandowsky and Oberauer 2016). This is why, for example, Republican partisans are willing to ignore the scientific consensus existing around climate change (Wiest, Raymond and Clawson 2015). Given what we know about the general erosion of trust in expertise (Nichols 2017), can we say with confidence that people are willing to place their faith in experts and policy specialists in matters relevant to foreign policy? If expertise is dead, we need to reevaluate the role of elites in public opinion formation more generally and on foreign policy, in particular.

The moniker "political elites" is often used as an amorphous black-box intended to represent the non-public in theories of foreign policy opinion formation. Who belongs in the box, whether these individuals are viewed the same way, and how the public treats different varieties of expertise and experience are not well understood. Whether this supposed deference to elites exists today, or ever existed, is an empirical question. In the next section, we unpack the contents of this black box, layout a theoretical framework that ties what we know about expertise and partisanship to foreign policy opinion formation, and delineate a set of testable hypotheses. 


\section{Who is Elite?}

The theory built in this section relies on familiar scaffolding. Dual-process theories of attitude formation provide a framework for understanding the importance of source cues in opinion formation (Bullock 2011, 498). These theories posit that persuasion can occur through systematic processing, where individuals check new information against stores of existing knowledge, or heuristic processing, where people rely on simple decision rules to decipher the validity of new information (see Chaiken and Trope 1999). Because people are relatively uninformed about international affairs, they lack the knowledge or motivation to systematically evaluate foreign policy issues. This is why the source of the information is so important.

Elite cue theories posit that the public relies on the "unknown others" described by Zaller $(1992,7)$ in heuristic information processing. In the absence of requisite knowledge, average citizens rely on elite cues because the information contained in these cues allow them to feel confident about the views they adopt without exerting the effort necessary to form systematic conclusions (Petty and Cacioppo 1986). People perceive elites as having unique knowledge and expertise that lend elite perspectives credibility (see Downs 1957; Lupia and McCubbins 1998; Robinson 2018). Here, credibility refers to the quality of being trustworthy or believable (Kouzes and Posner 2011; Lupton 2020). This perceived credibility makes the information elites disseminate more likely to move public opinion (Page, Shapiro and Dempsey 1987; Druckman 2001; Hwang 2013). Even if signals from an individual's social network have a larger effect on an individual's opinions about politics (Kertzer and Zeitzoff 2017), these perspectives likely originated among elites (Zaller 1992) and the platforms available to elites allow them to have a broader influence than any non-elite individual that might express a political opinion. We do not contest any of the basic precepts of these arguments but, instead, argue these precepts require refinement. 


\subsection{Elite Knowledge and Elite Credibility}

We begin our argument with a stipulatory premise. People can distinguish elites based on elites' vocations. Here, we intend the most basic definition of vocation. An elite's vocation is their trade or profession. If a person can comprehend the differences between Republicans and Democrats, it stands to reason they should also be capable of comprehending the differences between a senator and a professor. We do not presume a sophisticated understanding of elite professions. We do not think, for example, that the average American knows the differences among the subfields of political science but we do think it is reasonable to assume most people know that political science professors work at universities. If people can perceive the differences among elite's vocations, it follows that these perceived differences may be consequential for public perceptions of elites.

An elite's vocation is an important feature of an elite source que. The vocation provides information about the type of information that an elite has access to and the type of knowledge the elite can bring to bear on a particular policy topic. To demonstrate our point, we will compare four prominent groups of elites: elected officials, academics, career government officials, and members of the media. These vocations signal different levels of access to policy relevant information and policy relevant knowledge. These, in turn, confer different levels of credibility to these different classes of elites. These groups are not viewed as equally credible because they are not viewed as equally knowledgable.

We begin with the quintessential class of the political elite, elected officials (Lasswell 1936; Nadel 1956; Zuckerman 1977; Bullock 2011; Kertzer and Zeitzoff 2017). For now, we will set aside the obvious importance of partisanship to focus on the credibility-enhancing effects of holding elected office. This vocation lends credibility in two respects. The first is relatively minor. There is a naïve view of American democracy that suggests elected officials command some level of respect from the public by virtue of holding elected office. School children are taught, and adults are sometimes admonished, that we should respect senators, mayors, and presidents because we should respect the titles of their offices. As the events of January 6, 2021 demonstrated, such veneration 
for the symbols of elected office are hardly universal but the significance of this respect shouldn't be dismissed enitrely.

The second source of credibility is more relevant. Elected officials often have, or are assumed to have, access to specialized information not available to the public. For example, the president, his cabinet, and members of Congress that sit on relevant committees receive special, and sometimes classified, briefings about international affairs. The intelligence apparatus that collects and processes this information is vast and sophisticated. When the intelligence community is operating at its full potential, the information it provides to elected officials is as high resolution, and as timely, as any information available. This access to privileged information separates members of Congress from the public and lends the perspectives they share on international affairs credibility.

Next, we consider the class of political elites that Zaller (1992, 7) refers to as "experts" and "policy specialists." 3 Experts and policy specialists derive their credibility from their qualifications and credentials. We will differentiate two types of policy specialists.

One group of policy spealisits derives their qualifications from formal education. All academics, and some members of the policy community, go to graduate school to receive advanced degrees. Being a "Doctor of the Philosophy of" or even a "Master of" distinguishes these indviduals from people that lack these credentials (Nadel 1956). Individuals that have devoted time to the formal study of complex policy issues are percieved as having academic knowledge that enhances their perceived credibility. For example, Hiscox $(2006,775)$ examines the effects of question framing on public support for free trade and finds evidence that people are more likely to support free trade policies when they are told the policies are endorsed by Noble Prize winning economists. This is an extreme example but it highlights that academic credentials are perceived. We argue that more conventional academic credentials enhance perceived credibility in the same way.

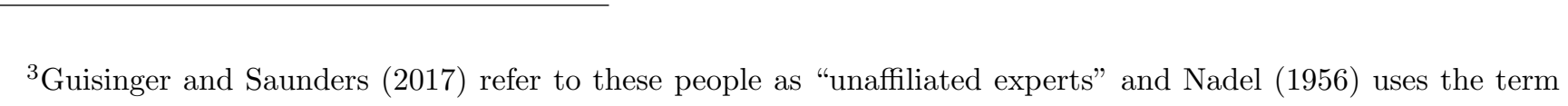
"specialized elites."
} 
Another group of policy spealisits derives their qualifications from experience. People that have had long careers in a policy area are perceived as having experiential knowledge that enhances their perceived crebility. Economists who have had long careers at the Federal Reserve or Treasury Department and analysts with careers in the intelligence services or the military derive credibility from the esteem of their former posts. The power of their opinions comes from the knowledge that the person (A) had the skills and intelligence necessary to achieve the post, and (B) likely cultivated a substantial amount of topical knowledge while holding the post. This is why cues from former military officers are influential in defense policy and military interventions (Lupton 2017; Golby, Feaver and Dropp 2018). Though these individuals may lack a formal educational credential, their specialized experience has the same credibility-enhancing utility.

The knowledge gained through academic toil, public service, or private enterprise lends credibility to experts and policy specialists for two reasons. First, their opinions and judgements are viewed as more reliable because they have a sharper set of tools with which to process complex information about international affairs. This point is highlighted by the monikers. Experts have expertise and policy specialists have special knowledge. Second, these individuals derive credibility from their perceived objectivity. Their ethos comes from their profession. While people can dispute information, it is much more difficult to dispute one's credentials or experience. This is, in part, what makes academic knowledge and experiential knowledge so credible. In the absence of a partisan designation suggesting otherwise, one assumes experts commentate on topics because of their interest in the topic. This is why these people are regularly asked to provide Congressional testimony on policies associated with their areas of expertise (see Jacobs and Page 2005).

The final class of elites we consider is media elites. Media elites are professional journalists or political pundits who offer commentary on politics and international events. For our purposes, we will use "media" to refer to information distributed through all major news outlets including newspapers, cable news networks, and professional news internet platforms. Members of the media do not have access to classified information and most members of the media do not have specialized policy knowledge or expertise. What sets them apart from the general public is their vocation as 
aggregators and disseminators of political information. These individuals stand astride the torrent of complex information about politics and foreign policy that most Americans view as overwhelming. Their apparent mastery of this information, whether pukka or postured, lends members of the media a modicum of credibility.

We have explained why elected officials, the different types of policy experts, and members of the media are perceived as credible but we do not argue that these groups of elites are equally credible. Access to information and knowledge seperates these individuals from common members of the public but the public does not percieve these groups as equally knowledgable or as having access to the same quality of information. These differences suggest a hierarcy of perceived credibility.

The media elite are perceived as the least credible among the three classes of elites. Not only do most members of the media lack access to specialized information or knowledge, most media outlets are subject to criticisms of partisan bias. We will address the issue of partisanship below, but the mere suggestion of systematic bias in the media has the effect of diminishing media credibility. The ability to distill critical ideas and share them with the public is where members of the media derive their credibility. The possibility that members of the media might be withholding information to serve an agenda is credibility-reducing.

The media credibility deficit is demonstrated by the need for media outlets to constantly advertise their credibility as they endeavor to differentiate themselves from alternative media sources. Fox News Channel famously advertises itself as "Fair and Balanced." The New York Times Slogan is, "All the News That's Fit to Print." Media outlets also attempt to bolster their claims of credibility by altering their curation strategies. For example, the CNN has gone to great pains in recent elections to present multiple partisan perspectives, sparking criticism that their efforts to appear balanced create a platform for misleading perspectives and information. The "panelization" of cable news has become a more popular trend, with news networks scheduling politicians, former career officials, and academics to appear alongside normal media commentators to generate an air of credibility that would be absent if pundits were at the dais alone (Farhi 2018). The fractured 
nature of the media environment and the general perception that one must be careful when processing information dissimenated by members of the media put this group of elites at a disadvantage compared to elected officials and policy experts.

With media members slated as the clear also-ran amongst the group, we are left with the interesting problem of comparing the perceived credibility of elected officials and policy experts. At the outset, we will say that we have no expectation of a difference between academics and career professionals. Whether people value academic knowledge or experiential knowledge more likely varies from subject to subject. We will speculate on the potential differnce in our concluding remarks but we will treat academics and career officials as a single class of elites for now. This choice is motivated less by the similarities amongst academic and career professionals as elites and more by the differences between these policy speacialists and elected officals.

The difference in the perceived credibility of policy spealists and elected officials is a function of the difference in the sources of their perceived credibility. Policy specialists derive their credibility from knowledge while elected officals derive most of their credibility from access to information. The information is specialized, which makes elected officials more credible than members of the media, but they are subject to the same skepticism as members of the media. Elected officials are the quintisential class of political elites but they are also quintessentially partisan. They literally arrived at their positions by dint of their membership to a political party. Certainly, politicians can be netural purveyors of information but perceptions of the information they purvey will always be colored by partisan cynicysm. The knowledge that policy experts gain from education and experience will never be subject to the same level of dubiety because the incentives they have to misrepresent the truth are not as obvious to the public and, perhaps, the professional incentives they have to be forthright with the public are perceived as well. This intuition informs a specific, testable, hypothesis about the relative credibility of these three groups. 
$H_{E}$ - The Elite Credibility Hypothesis: Unaffiliated experts should be viewed as more credible than politicians and both groups should be viewed as more credible than members of the media.

Before moving forward, we think it apposite to highlight the nature of this hypothesis and the attendant theoretical implications. Our elite credibility hypothesis is deliberately complex. It suggests a specific hierarchy among the groups of elites. This hierarchy makes this research hypothesis easier to reject because their are a range of alternatives. This hypothesis fails if (A) we are incorrect about the relative credibility of these different types of elites, or (B) any of the groups of elites are viewed as equally credible. As such, the knowledge produced by the evaluation of this hypothesis is more vivid than what might have been produced had we taken the less ardous rout of postulating that each of these groups are perceived as credible and then attempted to draw ad-hoc inferences about the relative crediblity of the groups after the fact. The preceding exposition about sources of elite credibility and the relative perceptions of these sources of credibility should offer credence to our claim that we are not interested in simply playing the results. With this in mind, we think the contribution of our elite credibility hypothesis would be diminished if the significance of elite vocation as a source cue were not placed in the obvious context within which this element of elite credibility is evaluated, the context created by partisanship.

\subsection{The Partisan Context}

While the source of a person's knowledge and credibility is important, partisanship is essential to understanding the role of credibility in public opinion formation. This is highlighted by the fact that politicians are often referred to as "partisan elites" (e.g. Bisgaard and Slothuus 2018, Peterson 2019) in applied work. To be an elected official in the United States is to be a partisan elected official. The perceived partisan affiliation of any politician, media member, or political expert will play a role in determining perceptions of credibility along with the aforementioned credentials \begin{tabular}{|l|l|l|l|}
\hline Auerbach and Bloch-Elkon 2005; & Baum and Groeling 2009; & Cavari and Freedman 2019).
\end{tabular} 
Voters are skeptical of the credibility of opposition politicians (Hayes 2005). This skepticism not only applies to domestic politics but to foreign policy positions as well Gelpi 2010, 108). This turns the naïve view of politics on its head. When we remove the veil of naïvity, we realize elections give elected officials incentives to misrepresent the specialized information they have access to. This is not necessarily an indictment of their character as much as a sober assessment about contemporary politics. Politicians in the US must rise through partisan institutions. They require endorsements from other partisans and resources from groups and firms to fund their campaigns. The partisan media environment reinforces these incentives.

Partisanship affects perceptions of other elites as well. Public perceptions of partisan bias in the media are well documented (Lee 2005; Stroud and Lee 2013; Lin, Haridakis and Hanson 2016). People are more likely to view media sources as biased when information from those sources does not conform to their political views (Coe et al. 2008). Partisanship influences the willingness of individuals to accept consensus. This is why Republican partisans have been unwilling to accept the scientific consensus on climate change (Bolsen and Druckman 2018). Similar effects have been shown for partisan perceptions of the economy (Enns, Kellstedt and McAvoy 2012) and the military (Burbach 2019).

In all these cases, partisan motivated reasoning causes people to view information and expertise emanating from opposition partisans as questionable and the same type of information from their co-partisans as reliable (Kraft, Lodge and Taber 2015). Bisgaard $(2015,850)$ shows this kind of reasoning is highly adaptive and has resonance across many issues and settings. The partisanship of the source becomes an indictment on the objectivity and reliability of the source and a reason to ignore the accuracy or timeliness of the information. This is the basis for the second hypothesis.

$H_{2}$ : Co-partisan endorsements should be viewed as more credible than nonpartisan endorsements and both endorsements should be viewed as more credible than opposition-partisan endorsements. 
After presenting our two hypotheses, we would like to highlight two important facets of our predictions. First, we do not propose an interactive hypothesis. This is because we do not believe they interact. Being a Republican or a Democrat does not eliminate the fact that an elite has a PhD or served in the military, for example. Rather, we believe these two facets run parallel to each other. This informs our research design in the next section. Second, the construction of our hypotheses sets a very high bar for our analysis. The ordered nature of our hypotheses, with some elites being viewed as more credible than others, requires our evidence support this order for our hypotheses to hold. Simply put, our hypotheses could be derailed or undermined in multiple ways. For example, there is a cynical perspective of American politics suggesting partisanship has become so extreme that expert knowledge doesn not matter any more. This view is consistent with public intellectuals who tout the death of expertise (e.g., Nichols 2017). For our theory to be correct, both our hypotheses must be supported.

\section{Research Design}

We test the hypotheses presented in the last section using a $4 \times 2$ between-group fractional-factorial survey experiment. We briefly describe the experiment here. To conserve space, we leave detials about the fractional-factorial design, the choices we made about the content of the treatments and the treatments theselves, and our scaling choices to the appendix.

We randomized participants into one of eight experimental conditions where they read about a hypothetical economic sanctions episode involving the United States and Brazil. We use a sanction episode because sanctions represent a moderate form of foreign policy intervention that is less costly than troop deployments but more costly than diplomatic pressure (Webb 2018). The precipitant event for the episode is the movement of Brazilian troops into Bolivian territory, a violation of territorial integrity that is plausibly salient to the participants but would not necessitate more acute intervention by the United States Ang and Peksen 2007). Members of Congress respond by 
drafting sanctions legislation. The source of the negative political commentary about the proposed legislation is the experimental treatment.

There are two experimental factors: vocation and partisanship. There are four levels to the Vocation Factor. The individual offering negative commentary on the proposed sanctions is either a retired general, a Harvard professor, a senator, or a cable news anchor. We don't include a control condition omitting the political commentary. Instead, we use the senator as a baseline category. We do not include a true control for vocation as this would be highly unrealistic given how elite commentary is actually given, where indviduals are idenitied by their vocation. Furthermore, our hypotheses are about comparisons among political elites. We argue that senators should have a credibility deficit compared to the independent experts and should be viewed as more credible than the cable news anchor. If this is true, the retired general general and the Harvard professor should be perceived as more credible than the senator and the cable news anchor should be perceived as less credible than the senator.

There are two levels of the Partisanship factor: partisan and control. In the partisan conditions we designate the commentator as Republican or the senator as Republican. In the control conditions we simply say that the commentators are "political commentators" and we omit the partisanship of the senator. We do not include the partisanship factor in our analysis as a Republican dummy variable. Instead, we use participant responses to questions about partisanship to code the conditions as co-partisan or opposition-partisan. This strategy reduces the size of the experiment. We have no expectation that the direction of the partisanship will effect evaluations, only the designation of the partisan elite as opposition-partisan or co-partisan.

The outcome of interest is participant perceptions of elite credibility. As noted earlier, past work indicates that the influence of elites derives primarily from their authority and expertise. Accordingly, we first directly consider the extent to which participants view Michael Johnson - the elite in our study - as "credible." The wording of the question is: 
How credible do you think Michael Johnson, and people like him, are to speak to foreign policy issues like the conflict between Brazil and Bolivia and the U.S. response?

$$
\text { (Not Credible) -5, -4, -3, -2, -1, 0, 1, 2, 3, 4, } 5 \text { (Very Credible) }
$$

The estimands of interest are sample average treatment effects (SATEs) for the levels of the experimental factors. We estimate these effects using ordinary least squares (OLS) regression. We are interested in the SATEs because there is not a coherent inferential target for the population average treatment effect (PATEs). We are literally providing participants with fake news. Understanding how the population responded to a fictitious event at a single point in time is of little interest. Experiments like the one we use in this study are more interesting in terms of what the differences between the levels of the experimental factors tell us about people in general, rather than what the sample tells us about the population (Calder, Phillips and Tybout 1981). This intuition informs our sampling decisions.

We recruited a convenience sample of 2,055 voting age US adults using Amazons Mechanical Turk (MTurk) $4^{4}$ MTurk is an online marketplace where "task creators" (requesters) pay workers to complete Human Intelligence Tasks (HITs). These workers are not randomly drawn from the U.S. population. They select into the survey and are compensated after completing the survey. That being said, our sample population largely mirrors the demographic distribution of American adults on metrics such as gender, race, education attainment, and partisanship. For example, across our sample $54.73 \%$ of participants identify as female, $12.02 \%$ identify as Black or African American, and $58.46 \%$ hold a Bachelor's degree or higher. Politically, 27.25\% of our sample identify as Republican, while $43.50 \%$ identify as Democratic.

\footnotetext{
${ }^{4}$ The survey was available on MTurk on September 30, 2019. This survey received IRB approval.
} 
Some social scientists have expressed concern that inferences from MTurk convenience samples do not generalize to the population. While we are happy to acknowledge that we are using a convenience sample, we do not view this as a limitation of the study. Again, there is not a PATE we are trying to recover as an inferential target. Also, there has been a wave of empirical evidence over the past several years showing that results from MTurk Mullinix et al. 2015; Coppock, Leeper and Mullinix 2018; Coppock 2019) and student (Lupton 2019) convenience samples correspond to results from experiments conducted using more expensive nationally representative samples. Accordingly, we believe our sample is appropriate to our question and to test our hypotheses.

\section{Results}

Table 1 presents a series of OLS regressions that subject our hypotheses to emperical scrutiny. The slope coefficients in the regression models are isomorphic to the standard difference of means tests used to calculate the SATEs (King 1986). We have elected to present the regression results because this is the most efficient manner to display formal tests of all the comparisons simultaneously. The slopes for the partisanship coefficients are the differences between each level of the partisanship factor and the omitted category, the non-partisans. The slopes for the vocation coefficients are the difference in means for each vocation compared to the omitted category, the senators. A statistically significant slope coefficient denotes a statistically significant difference between the means. We present results for the differences over the levels of the partisanship factor, results for differences over the levels of the vocation factor, and then a model that includes both factors. We present two versions of each regression, one version that includes a battery of common demographic variables and one that does not. To conserve space, we leave the discussion of the controls to the appendix.

The results presented in Table 1 support each element of both hypotheses and these inferences are robust to specification. All the hypothesized patterns appear in the data and all the differences are statistically significant. 
Table 1: Ordinary Least Squares Models of Credibility

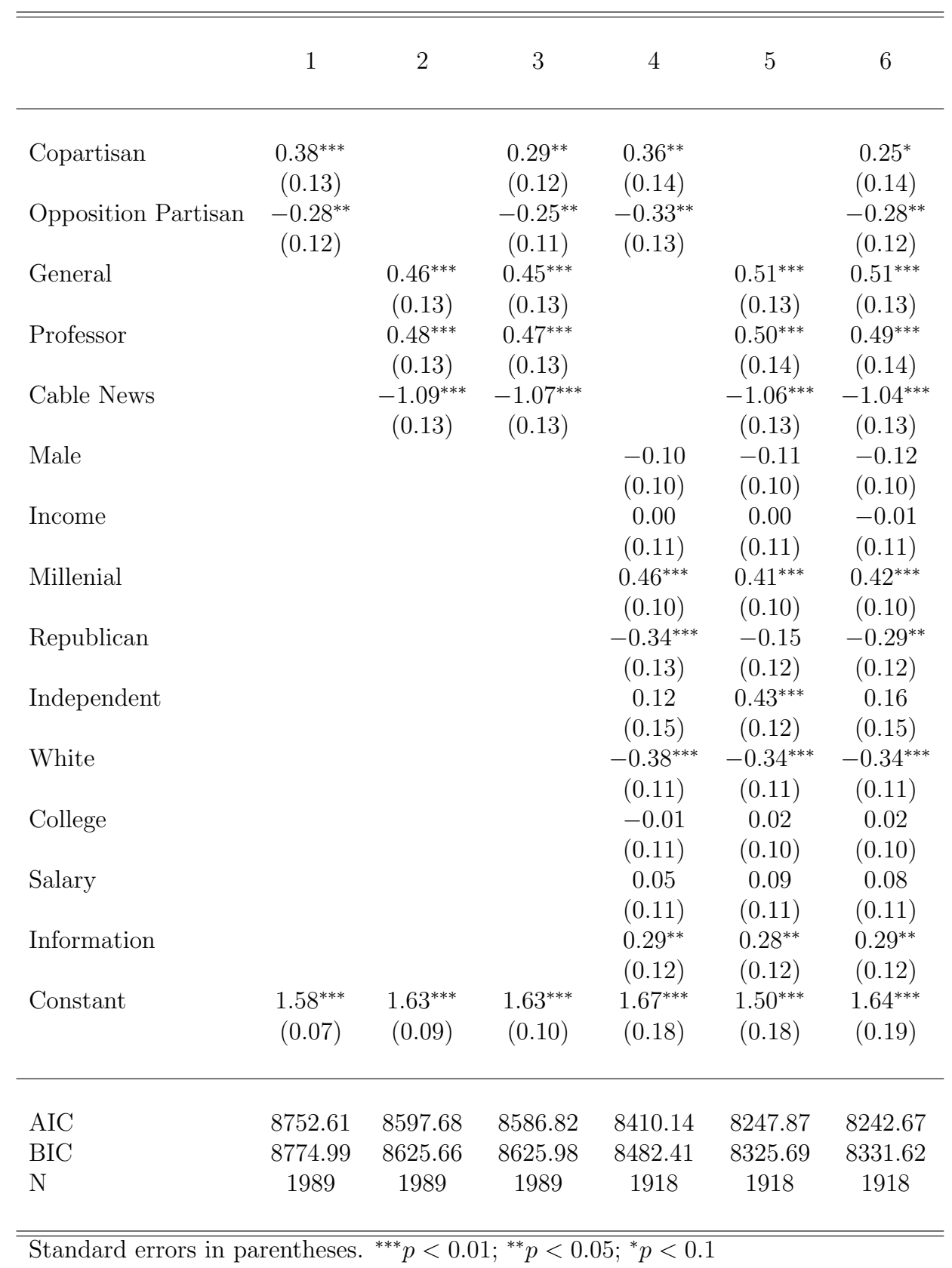


Beyond the correspondance between our hypotheses and the results, there are two more results in Table 1 that warrant discussion. First, there do not appear to be important differences between the unaffiliated experts, professors and retired generals. In the models that don't include demographic covariates, the coefficients for professor are slightly higher than the coefficients for the retired generals. In the models that do include demographic covariates, the coefficients for the retired generals are slightly higher than the coefficients for the professors. These comparisons are meaningful because the experimental factors all vary in the same way, taking on values of 0 or 1 , and they are all interpreted with respect to the same dependent variable. The differences between the unaffiliated experts are trivial across the different models. The differences between these experts and the other groups of elites are significant across all the specifications.

The absolute values of the different effects are also worth mentioning. The largest effect presented in Table 1, by far, is the negative effect of the Cable News anchor vocation. The effect is twice as large as the positive effect of being an unaffiliated expert and three to four times larger than the partisanship effects. The effect of being a retired general or a professor is about twice as large as the difference between being a co-partisan and a non-partisan or the difference between being a non-partisan and an opposition partisan. Across all conditions, the most important determinant in how the public perceives partisan elites is elite vocation. Note, this does not mean that an opposition-partisan senator is perceived as more credible than a co-partisan news anchor. We have no expectation that the factors interact but they certainly are not evaluated in isolation.

This highlights a need for a more nuanced depiction of the results. It is difficult to evaluate the relative credibility of the elites described in our experiment by looking at the coefficients alone. To make the comparison of the overall credibility of the elites in the experiment easier, we present the predicted values of credibility from the regression models in Figure 1. These are the predicted values of the level of credibility based on the different combinations of the experimental factors. The predictions are based on the results from Model 6 in Table 1 . This model was chosen because it is the model that fits the data best according to the AIC and BIC of the two models that include both experimental factors. The predictions allow one to easily compare the perceived credibility of 
the different elites from the different experimental conditions. The points are the predicted values. The intervals around the points are the $95 \%$ confidence intervals for those predictions.

Figure 1: Predicted Perceived Credibility of Elites Across Partisanship and Vocation

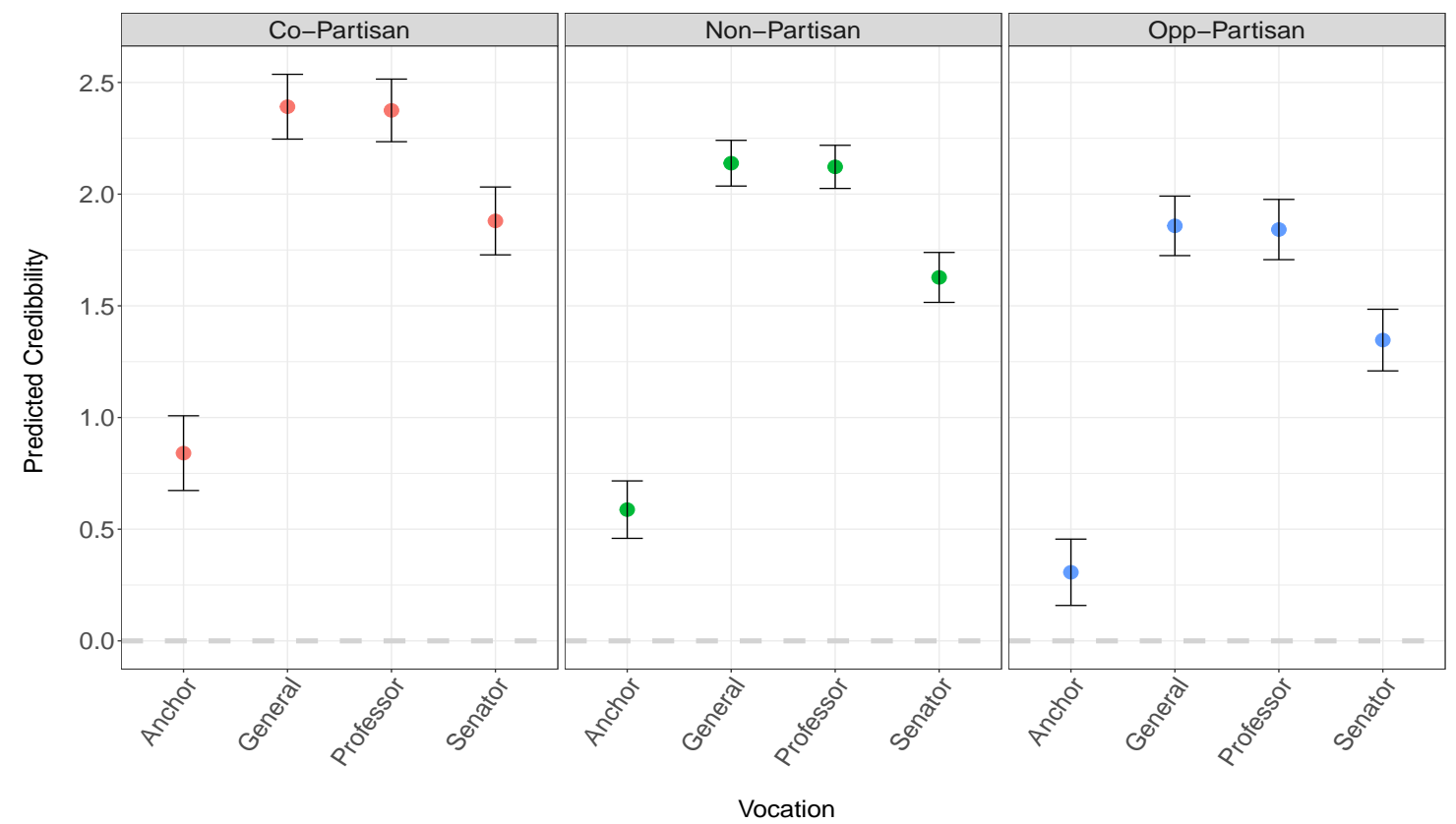

Note: The points are the predicted values of elite credibility. The predictions are based on estimates from ordinary least squares (OLS) regression models of participant responses to the following question: How credible do you think Michael Johnson, and people like him, are to speak to foreign policy issues like the conflict between Brazil and Bolivia and the U.S. response? The responses range from (Not Credible) - 5 to (Very Credible) 5. The vertical lines are $95 \%$ bootstrapped confidence intervals for the predicted values.

The predictions in Figure 1 provide a clearer depiction of the results presented in Table 1 . The unaffiliated experts are perceived as more credible than the Senators and all three groups are perceived as more credible than the Cable News anchors. While the unaffiliated experts are viewed as more credible than the other vocations, the perceived credibility of academics whose elite status is a consequence of the academic knowledge cannot be distinguished from the perceived credibility of retired service people, whose credibility is based on their experiential knowledge. This pattern is consistent across the levels of the partisanship factor, though the perceived credibility of each type of expert is reduced as one moves from the co-partisan elites to elites where no partisanship was mentioned and falls again when one moves from the latter conditions to the conditions where the elites are from the opposition party. 
Another interesting result depicted in Figure 1 is one that is not readily obvious from the results presented in Table 1. All of the predicted evaluations are positive. To be sure, this is not a result relevant to either of our research hypotheses, but it is a result that bears discussion as it is relevant to the broader issue at hand. The participants rated the elites in the different conditions on an eleven-point scale that ranged from -5 (Not Credible) to 5 (Very Credible), with the middle value of the scale (0) clearly identifying the difference between positive and negative evaluations. The somewhat surprising result from the analysis is that the elites are always predicted to have a positive evaluation. While our analysis is, in part, motivated by the observation that it might be incorrect to treat all the elites that Zaller (1992) identifies the same way; these predicted values suggest that, in some respects, Zaller is correct. All of these people, regardless of vocation or partisanship, are viewed as somewhat credible on average. That is, they are all elites. If expertise was truly dead, and the sources of credibility identified by Zaller no longer mattered, at least one of these predictions would be negative. That is not the case. The public views elites, on average, in a positive light; at least as it pertains to their credibility to speak to international events. Where Zaller is wrong, or at least incomplete, is the fact that there are still important differences among these different elites that should be accounted for in theories that presume to explain public perceptions of foreign policy based on public perceptions of elites.

The predictions also facilitate important comparisons among the different vocations across the levels of the partisanship factor. While we observe the same general pattern within each level of the partisan factor, when we compare the different vocations across the factors we find some meaningful comparisons. Take, for example, the perceived credibility of co-partisan senators and non-affiliated elites that are identified with the opposition party. Despite their experiential and academic knowledge, opposition-partisan experts are not viewed as more credible than a co-partisan senator. In some sense, this is not surprising. We know partisanship plays an important roll. Still, it is interesting to see how participants perceive these different experts described in the vignettes. On the other extreme, we see that there is no condition where a cable news anchor is viewed as more credible than an elected official, even one from the opposition party. This suggests there 
are important limitations to the ability of the media to control the narrative around international events.

Taken together, the results from the experiment provide strong support for the hypotheses we outline above. The results also have important implications for ongoing debates about the roles of elites in foreign policy and the supposed death of expertise. We will discuss these implications in more detail below. Before we get there though, we want to spend a little more time unpacking the causal mechanism behind these results, elite knowledge.

\section{$6 \quad$ Elite Knowledge and Credibility}

Knowledge plays a critical role in the theory we develop to explain public perceptions of elite credibility. The different varieties of knowledge that serve as the basis for expertise are what motivated the ordered structure of our research hypotheses. We interpret the results presented in the last section as broadly consistent with this causal mechanism. Here, we probe the causal mechanism at the heart of the theory further by subjecting our interpretation to a useful stress test.

We propose an informal test of the causal mechanism. If our theory is correct, and public perceptions of knowledge are what shape public perceptions of credibility; we should be able to observe the same patterns we observed in public perceptions of credibility in public perceptions of knowledge. If some other underlying process explains the patterns we observe in public perceptions of credibility, we should observe either a series of null relationships in public perceptions of knowledge or some alternative pattern. To this end, we propose the following question as a measure of public perceptions of elite knowledge: 
How knowledgeable do you think Michael Johnson, and people like him, are to speak to foreign policy issues like the conflict between Brazil and Bolivia and the U.S. response?

$$
\text { (Not Knowledgeable) -5, -4, -3, -2, -1, 0, 1, 2, 3, 4, } 5 \text { (Very Knowledgable) }
$$

The wording is almost identical to the wording of the credibility question. Participants are asked to evaluate how knowledgable our protagonist, Michael Johnson, is on an eleven point scale that ranges from not knowledgable (-5) to very knowledgable (5). The wording and measurement strategy are valid for all the previous reasons outlined above. We highlight the elite trait we want the participant to evaluate, we allow the participant to assign positive or negative values for positive or negative evaluations, and we have a middle category that the participant can select if they are ambivalent or indifferent about this evaluation.

Some might object to using a scale that is so similar to the previous question. Aren't we just measuring the same thing? But that is precisely the point. We think we are but we are not sure. If the participants read this question after reading the credibility question and interpreted this question as meaning essentially the same thing, then we have more, albeit informal, evidence that is consistent with our argument that perceived knowledge is what drives perceived credibility. If there are significant deviations in the responses, it suggests that knowledge means something different, or nothing at all, with respect to credibility. This question was asked after the credibility question to ensure that we were not priming participants to think about knowledge prior to thinking about credibility. We use the same analysis as before. For the sake of brevity, we only presented the predicted values from the OLS regression model that includes the levels of both experimental factors and the demographic covariates, similar to the results presented in Figure 1 .

The predicted values of perceived elite knowledge are presented in Figure 2. The results support our conjecture that perceptions of elite knowledge are the causal mechanism that shape 
Figure 2: Predicted Perceived Elite Knowledge of Elites Across Partisanship and Vocation

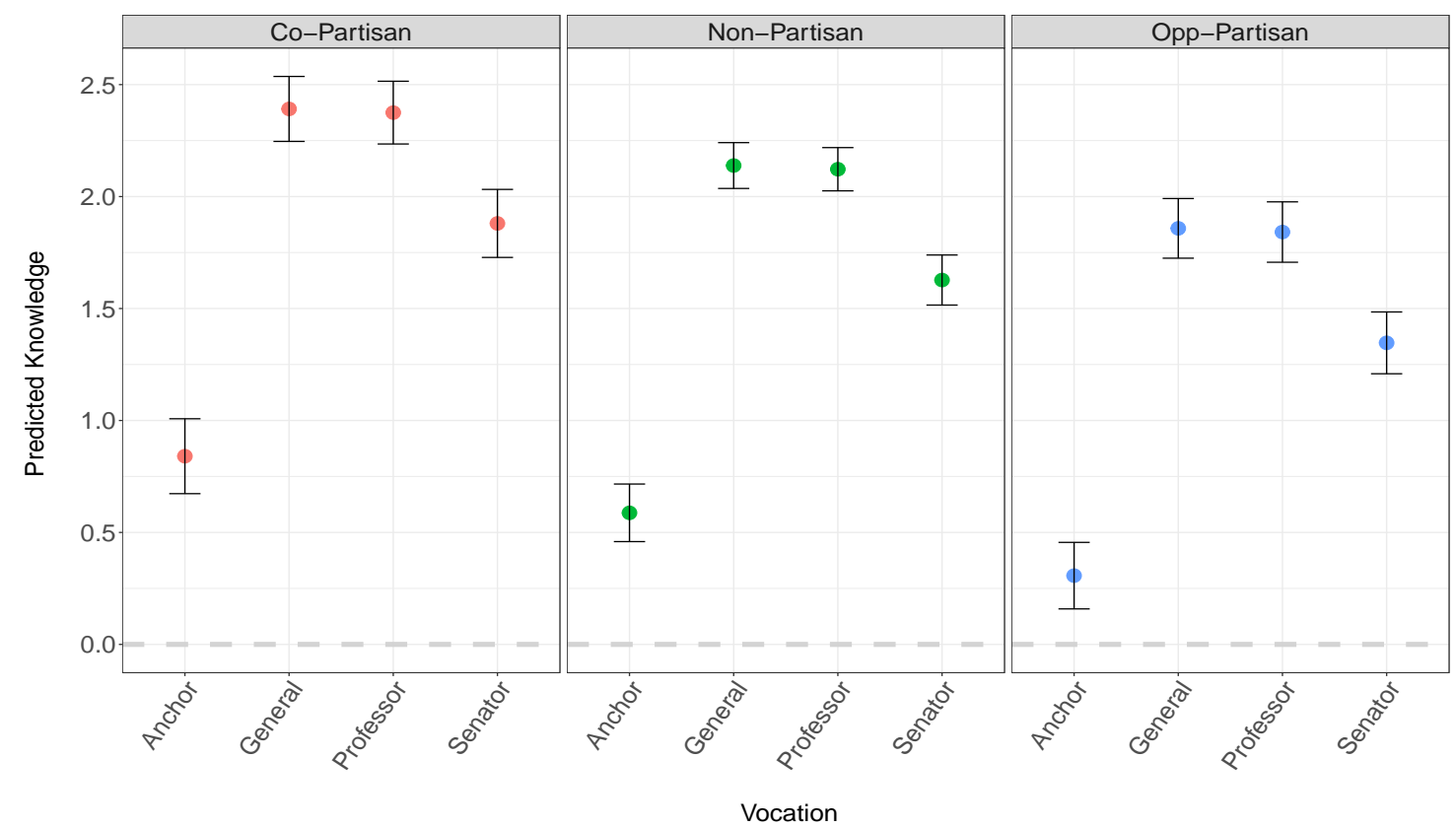

Note: The points are the predicted values of elite knowledge. The predictions are based on estimates from ordinary least squares (OLS) regression models of participant responses to the following question: How knowledgeable do you think Michael Johnson, and people like him, are to speak to foreign policy issues like the conflict between Brazil and Bolivia and the U.S. response? The responses range from (Not Knowledgeable) - 5 to (Very Knowledgeable) 5 . The vertical lines are $95 \%$ bootstrapped confidence intervals for the predicted values.

public perceptions of elite credibility. The patterns of predicted knowledge mirror the patterns in predicted credibility depicted in Figure 1 .

The correspondance of the patterns presented in Figures 2 and 1 is consistent with our underlying theory. Public perceptions of elite knowledge is what sets elites apart from the rest of the public and these perceived levels of knowledge give elites the credibility they need to shape public perceptions of foreign policy. It would be incorrect to say that all elites are viewed the same way but it is also incorrect to say that elite knowledge doesn't matter to the public. If expertise was dead, elite expertise wouldn't confer credibility. The evidence we provide here provides reasons for optimism. 


\section{Discussion and Conclusion}

In The Death of Expertise, Nichols offers a fervent eulogy for the role of elite knowledge in American political life. He argues that Americans have become proud of not knowing things because rejecting the "advice of experts" allows people to "insulate their increasingly fragile egos from ever being told

they're wrong about anything" (Nichols 2017, x). In the era of sharp partisan divisions, it's easy to see how one could reach that conclusion and why one might find such an argument compelling. Yet, there is an important irony to this lament. Nichols provides no scientific evidence that the public no longer cares about expertise, only a compendium of annecdotes consistent with his conclusions. Other works arguing expertise is dead suffer from a similar problem (Hayes 2012; Kakutani 2019). Even more so, these arguments are inconsistent with a substantial amount of existing research about the roles of elites in shaping public opinions about foreign policy. Yet, what makes these arguments so compelling is the apparent lack of interest the public has in the views from two groups: members of the political opposition and members of the media. The theory and evidence we provide in this paper addresses this apparent incongruity.

Not all elites are viewed with equal deference. Our study produces two findings relevant to this conclusion. First, we show that partisanship does indeed shape perceptions of elite credibility. As predicted, co-partisans are evaluated as more credible than non-partisans, and opposition partisans are evaluated as least credible. Second, we find support for our vocational hypothesis. Unaffiliated experts are perceived as more credible than political elites, while news elites are viewed as less credible than political elites. Our study, therefore, shows that not all elites are viewed as equals. This does not mean that elites don't matter, only that one cannot hope to have the same influence on public perceptions of foreign policy simply by reporting on what they view as the facts on the ground. Our results show that elite status is conferred through credentials. One cannot simply appear to have more information. The public must perceive the individual as having more command of that information. To this end, we further directly challenge one of the key arguments of underlying those who purport the death of expertise - that "citizens do not understand, or choose not to understand, 
the difference between experts and elected officials" (Nichols 2017, 218-219). In sharp contrast, we show that participants in our study clearly differentiated between various types of elites.

These findings are buoyed by the structure of our hypotheses. We not only propose that perceived knowledge and partisanship have hypothesized effects on perceptions of elite credibility, we proposed hypotheses that outlined the specific structure of the deference given to different types of elites. If any part of the theory was incorrect, we would have rejected these well-defined hypotheses. As such, we believe the evidence for the hypotheses presented in this paper represents more than a simple affirmation of our simple conjectures. Rather, the evidence for these wellstructured hypotheses should be viewed as robust evidence consistent with our theory about the role of knowledge. Add to that the correspondence between public perceptions of knowledge and public perceptions of credibility, and one finds robust evidence against the death of expertise conjecture, at least in the realm of public opinion on foreign policy. Furthermore, the positive evaluations of experts across the conditions of the experiment also provide evidence against the death of expertise argument. Elites of all kinds, even opposition partisan cable news anchors, were viewed positively, on average. This suggests that negative partisanship does not overwhelm the role of elite knowledge in shaping public perceptions of elites and elite credibility.

Our results also have important implications for research on the study of elites in public opinion formation more generally. Zaller (1992) lists elected officials, journalists, academics, and policy experts among the types of individuals that can have an outsized influence on public opinion formation through their status as elites. While the positive evaluations of these individuals in our experiments, on balance, affirm Zaller's conclusions; the differences among the elites in our experiment suggest that this theory may be incomplete. Some experts play a larger role than others. This has important implications for current work on the sources of opinion formation. For example, Kertzer and Zeitzoff (2017) provide evidence that the opinions shared by one's friends and family play a more important role in opinion formation than elected officials. This may be true but this does not mean that so called mesofoundations matter more than all forms of elite communication. 
These findings are also relevant to research that uses elite subject pools. Proponents of this research suggest that the perspectives of policy elites are important because they have more ability to shape public opinion about foreign policy. On the one hand, the evidence provided here bolsters this line of argument. We find evidence that the elite status of policy experts has a larger effect on public perceptions of policy than politics. On the other hand, our findings suggest a need for future research. Not all experts matter as much in all settings. Moving forward, scholars must explain why so-called elite subjects are important for the policy area at hand rather than assuming that their knowledge and status make them more-or-less important.

Before concluding, we think it is important to highlight the scope conditions for our findings. Our experimental evidence suggest that experiential and academic knowledge are stronger signals of credibility than mere access to information but this does not necessarily imply that academics and policy experts have a larger effect on opinion formation than members of the media or politicians. While academics and policy experts are viewed as more credible, the sizes of their platforms limit their ability to influence opinion formation. A Senator or a television-news personality may be viewed as slightly less credible on balance but the size of their platform likely affords them more opportunities to influence opinion. This, in turn, may explain why media elites and elected officials are less credible. Future research is necessary to evaluate these dynamics.

Finally, the results presented in this paper have a normative appeal. Expertise is not dead. Social scientists often joke that their work does not matter to members of the public. This is true insofar as the work is not read by the public but the results presented here suggest that academics are better positioned to influence public discourse about policy than other public intellectuals and members of the media. However meager our pay checks in the Academy, the results presented here indicate the public still values academic elites and the perspectives they offer. If we are unhappy with the public conversation about foreign policy, we need to get more involved in the public discourse about politics. We may have the ability to influence public debate after all. 


\section{References}

Aldrich, John H, Christopher Gelpi, Peter Feaver, Jason Reifler and Kristin Thompson Sharp. 2006. "Foreign policy and the electoral connection." Annu. Rev. Polit. Sci. 9:477-502.

Almond, Gabriel Abraham. 1950. "The American people and foreign policy.".

Ang, Adrian U-Jin and Dursun Peksen. 2007. "When do economic sanctions work? Asymmetric perceptions, issue salience, and outcomes." Political Research Quarterly 60(1):135-145.

Auerbach, Yehudith and Yaeli Bloch-Elkon. 2005. "Media framing and foreign policy: The elite press vis-a-vis US policy in Bosnia, 1992-95." Journal of Peace Research 42(1):83-99.

Baum, Matthew A and Tim Groeling. 2009. "Shot by the messenger: Partisan cues and public opinion regarding national security and war." Political Behavior 31(2):157-186.

Baum, Matthew A and Tim Groeling. 2010. "Reality asserts itself: Public opinion on Iraq and the elasticity of reality." International Organization 64(3):443-479.

Berinsky, Adam J. 2007. "Assuming the costs of war: Events, elites, and American public support for military conflict." The Journal of Politics 69(4):975-997.

Berinsky, Adam J. 2009. In time of war: Understanding American public opinion from World War II to Iraq. University of Chicago Press.

Bisgaard, Martin. 2015. "Bias will find a way: Economic perceptions, attributions of blame, and partisan-motivated reasoning during crisis." The Journal of Politics 77(3):849-860.

Bisgaard, Martin and Rune Slothuus. 2018. "Partisan elites as culprits? How party cues shape partisan perceptual gaps." American Journal of Political Science 62(2):456-469.

Bolsen, Toby and James N Druckman. 2018. "Do partisanship and politicization undermine the impact of a scientific consensus message about climate change?" Group Processes 6 Intergroup Relations 21(3):389-402.

Brennan, Jason. 2016. Against Democracy. Princeton University Press.

Bullock, John G. 2011. "Elite influence on public opinion in an informed electorate." American Political Science Review pp. 496-515.

Burbach, David T. 2019. "Partisan dimensions of confidence in the US military, 1973-2016." Armed Forces \& Society 45(2):211-233.

Calder, Bobby J, Lynn W Phillips and Alice M Tybout. 1981. "Designing research for application." Journal of consumer research 8(2):197-207.

Cavari, Amnon and Guy Freedman. 2019. "Partisan cues and opinion formation on foreign policy." American Politics Research 47(1):29-57.

Chaiken, Shelly and Yaacov Trope. 1999. Dual-process theories in social psychology. Guilford Press. 
Chanley, Virginia A, Thomas J Rudolph and Wendy M Rahn. 2000. "The origins and consequences of public trust in government: A time series analysis." Public opinion quarterly 64(3):239-256.

Coe, Kevin, David Tewksbury, Bradley J Bond, Kristin L Drogos, Robert W Porter, Ashley Yahn and Yuanyuan Zhang. 2008. "Hostile news: Partisan use and perceptions of cable news programming." Journal of Communication 58(2):201-219.

Coppock, Alexander. 2019. "Generalizing from survey experiments conducted on Mechanical Turk: A replication approach." Political Science Research and Methods 7(3):613-628.

Coppock, Alexander, Thomas J Leeper and Kevin J Mullinix. 2018. "Generalizability of heterogeneous treatment effect estimates across samples." Proceedings of the National Academy of Sciences 115(49):12441-12446.

Downs, Anthony. 1957. An Economic Theory of Democracy. Harper and Row.

Drezner, Daniel. 2017. The Ideas Industry. Oxford University Press.

Druckman, James N. 2001. "On the limits of framing effects: Who can frame?" Journal of Politics 63(4):1041-1066.

Druckman, James N, Erik Peterson and Rune Slothuus. 2013. "How elite partisan polarization affects public opinion formation." American Political Science Review 107(1):57-79.

Druckman, James N and Thomas J Leeper. 2012. "Learning more from political communication experiments: Pretreatment and its effects." American Journal of Political Science 56(4):875-896.

Enns, Peter K, Paul M Kellstedt and Gregory E McAvoy. 2012. "The consequences of partisanship in economic perceptions." Public Opinion Quarterly 76(2):287-310.

Farhi, Paul. 2018. "How breaking news got panelized: On cable, journalists and pundits increasingly share space." The Washington Post .

URL: https://www.washingtonpost.com/lifestyle/style/how-breaking-news-gotpanelized-on-cable-journalists-and-pundits-increasingly-share-space/2018/03/20/ b5fc36d8-2250-11e8-badd-7c9f29a55815_story.html

Gelpi, Christopher. 2010. "Performing on cue? The formation of public opinion toward war." Journal of Conflict Resolution 54(1):88-116.

Golby, James, Peter Feaver and Kyle Dropp. 2018. "Elite military cues and public opinion about the use of military force." Armed Forces $\&$ Society 44(1):44-71.

Grynaviski, Jeffrey D. 2010. Partisan bonds: Political reputations and legislative accountability. Cambridge University Press.

Guisinger, Alexandra and Elizabeth N Saunders. 2017. "Mapping the boundaries of elite cues: How elites shape mass opinion across international issues." International Studies Quarterly 61(2):425441. 
Gunther, Albert C, Cindy T Christen, Janice L Liebhart and Stella Chih-Yun Chia. 2001. "Congenial public, contrary press, and biased estimates of the climate of opinion." Public Opinion Quarterly 65(3):295-320.

Hayes, Christopher. 2012. Twilight of the Elites. Broadway.

Hayes, Danny. 2005. "Candidate qualities through a partisan lens: A theory of trait ownership." American Journal of Political Science 49(4):908-923.

Hetherington, Marc. 2015. "Why polarized trust matters." 13(3):445-458.

Hetherington, Marc J and Thomas J Rudolph. 2015. Why Washington won't work: Polarization, political trust, and the governing crisis. University of Chicago Press.

Hiscox, Michael J. 2006. "Through a glass and darkly: Attitudes toward international trade and the curious effects of issue framing." International Organization 60(3):755-780.

Holsti, Ole R. 2004. Public opinion and American foreign policy. University of Michigan Press.

Hooghe, Liesbet and Gary Marks. 2005. "Calculation, community and cues: Public opinion on European integration." European Union Politics 6(4):419-443.

Hwang, Sungwook. 2013. "The effect of Twitter use on politicians' credibility and attitudes toward politicians." Journal of Public Relations Research 25(3):246-258.

Jacobs, Lawrence R and Benjamin I Page. 2005. "Who influences US foreign policy?" American political science review 99(1):107-123.

Jentleson, Bruce W. 1992. "The pretty prudent public: Post post-Vietnam American opinion on the use of military force." International studies quarterly 36(1):49-74.

Jentleson, Bruce W and Rebecca L Britton. 1998. "Still pretty prudent: Post-Cold War American public opinion on the use of military force." Journal of Conflict Resolution 42(4):395-417.

Kakutani, Michiko. 2019. The Death of Truth. Tim Duggan Books.

Kavanaugh, Jennifer and Michael Rich. 2018. Truth Decay. RAND Corporation.

Kertzer, Joshua D and Thomas Zeitzoff. 2017. "A bottom-up theory of public opinion about foreign policy." American Journal of Political Science 61(3):543-558.

King, Gary. 1986. "How not to lie with statistics: Avoiding common mistakes in quantitative political science." American Journal of Political Science pp. 666-687.

Kouzes, James M and Barry Z Posner. 2011. Credibility: How leaders gain and lose it, why people demand it. Vol. 203 John Wiley \& Sons.

Kraft, Patrick W, Milton Lodge and Charles S Taber. 2015. "Why people "don't trust the evidence" motivated reasoning and scientific beliefs." The ANNALS of the American Academy of Political and Social Science 658(1):121-133. 
Kreps, Sarah. 2010. "Elite consensus as a determinant of alliance cohesion: Why public opinion hardly matters for NATO-led operations in Afghanistan." Foreign policy analysis 6(3):191-215.

Lasswell, Harold. 1936. Politics: who gets what, when, and how. McGraw-Hill.

Lee, Tien-Tsung. 2005. "The liberal media myth revisited: An examination of factors influencing perceptions of media bias." Journal of Broadcasting 8 Electronic Media 49(1):43-64.

Lewandowsky, Stephan and Klaus Oberauer. 2016. "Motivated rejection of science." Current Directions in Psychological Science 25(4):217-222.

Lin, Mei-Chen, Paul M Haridakis and Gary Hanson. 2016. "The role of political identity and media selection on perceptions of hostile media bias during the 2012 presidential campaign." Journal of Broadcasting \&6 Electronic Media 60(3):425-447.

Lupia, Arthur and Matthew McCubbins. 1998. The Democratic Dilemma. Cambridge University Press.

Lupton, Danielle L. 2017. "Out of the service, into the house: Military experience and congressional war oversight." Political Research Quarterly 70(2):327-339.

Lupton, Danielle L. 2019. "The External Validity of College Student Subject Pools in Experimental Research: A Cross-Sample Comparison of Treatment Effect Heterogeneity." Political Analysis 27(1):90-97.

Lupton, Danielle L. 2020. Reputation for Resolve: How Leaders Signal Determination in International Politics. Cornell University Press.

Milner, Helen V and Dustin Tingley. 2013. "Public opinion and foreign aid: A review essay." International Interactions 39(3):389-401.

Mosca, Gaetano. 1939. The ruling class: Elementi di scienze politica). McGraw-Hill.

Mullinix, Kevin J, Thomas J Leeper, James N Druckman and Jeremy Freese. 2015. "The generalizability of survey experiments." Journal of Experimental Political Science 2(2):109-138.

Nadel, Siegfried. 1956. "The Concept of social elites." International Social Science Bulletin 8(3):413424.

Nichols, Tom. 2017. The death of expertise: The campaign against established knowledge and why it matters. Oxford University Press.

Nisbet, Erik C, Kathryn E Cooper and R Kelly Garrett. 2015. "The partisan brain: How dissonant science messages lead conservatives and liberals to (dis) trust science." The ANNALS of the American Academy of Political and Social Science 658(1):36-66.

Page, Benjamin I, Robert Y Shapiro and Glenn R Dempsey. 1987. "What moves public opinion?" American Political Science Review 81(1):23-43. 
Pareto, Vilfredo. 1935. The mind and society: Trattato di sociologia generale. Harcourt, Brace and Co.

Parry, Geraint. 1969. Political Elites. Praeger.

Peterson, Erik. 2019. "The Scope of Partisan Influence on Policy Opinion." Political Psychology 40(2):335-353.

Petty, Richard and John Cacioppo. 1986. Communication and Persuasion. Springer.

Robinson, Michael. 2018. "Danger Close: Military Politicization and Elite Credibility." PhD Thesis, Stanford University.

Saunders, Elizabeth N. 2015. "War and the inner circle: Democratic elites and the politics of using force." Security Studies 24(3):466-501.

Stroud, Natalie Jomini and Jae Kook Lee. 2013. "Perceptions of cable news credibility." Mass Communication and Society 16(1):67-88.

Webb, Clayton. 2018. "Power Politics or Public Pandering? An Empirical Investigation of Economic Sanctions and Presidential Approval." International Interactions 44(3):491-509.

Wiest, Sara L, Leigh Raymond and Rosalee A Clawson. 2015. "Framing, partisan predispositions, and public opinion on climate change." Global environmental change 31:187-198.

Zaller, John. 1992. The nature and origins of mass opinion. Cambridge university press.

Zuckerman, Alan. 1977. "The Concept "Political Elite": Lessons from Mosca and Pareto." Journal of Politics 39(2):908-923. 